The Knowledge Engineering Review, Vol. 8:1, 1993, 91

\title{
CALENDAR ANNOUNCEMENT
}

June 1-4 1993

Sixth International Conference on Industrial and Engineering Applications of Artificial Intelligence and Expert Systems (IEA/AIE-93)

The City Chambers, Edinburgh, Scotland, June 1-4, 1993.

Sponsored by the International Society of Applied Intelligence and cooperated with major international organizations and universities, including ACM/SIGART, AAAI, IEEE Computer Society, ECCAI, CSCSAI, IAKE, INNS, JSAI, and Southwest Texas State University.

For further information, contact Dr. Moonis Ali, General Chair, IEA/AIE-93, Department of Computer Science, Southwest Texas State University, San Marcos, TX 78666-4616, USA. Tel: +1 512245 3409; Fax: +1 512245 3804; Email: MA04@SWTEXAS.BITNET. 